\title{
Prevalent Dengue Serotypes in and around Aurangabad, Maharashtra, India
}

\author{
Vanlalhmingthanpuii*, Jayshree B. Bhakre, Jyoti A. Iravane, \\ Ajit S. Damle and Pankaj A. Joshi
}

\author{
${ }^{1}$ Department of Microbiology, G.M.C Aurangabad, Maharashtra, India \\ ${ }^{2}$ Department of Microbiology, Indian Institute of Medical Science \& Research, \\ Aurangabad-Jalnaroad, Warudi.Tq, Badnapur, Maharashtra, India
}

*Corresponding author

\begin{tabular}{|l|}
\hline K e y w o r d s \\
DENV, NS1 \\
ELISA, RT-PCR \\
\hline Article Info \\
\hline $\begin{array}{l}\text { Accepted: } \\
15 \text { October } 2020 \\
\text { Available Online: } \\
10 \text { November } 2020\end{array}$ \\
\hline
\end{tabular}

\section{A B S T R A C T}

\section{Introduction}

Dengue virus causes dengue fever which is a febrile arboviral disease. ${ }^{(1)}$ Dengue virus is an enveloped RNA virus with a single positive strand. ${ }^{(2)}$ It is transmitted through the bite of infected Aedesmos quito. ${ }^{(3)}$ The genome is composed of three structural protein genes, encoding the nucleocapsid or core protein $(\mathrm{C})$, a membrane associated protein $(\mathrm{M})$, an envelope protein (E), and seven non-structural (NS) protein genes.

The non-structural (NS) proteins are NS1, NS2a, NS2b, NS3, NS4a, NS4b, and NS5 (WHO, 2014). NS1 is a highly conserved 
glycoprotein that seems to be essential for virus viability but has no established biological activity $^{(4)}$

There are four virus serotypes, which are designated as DENV 1, DENV 2, DENV 3 and DENV 4. Although all four serotypes are antigenically similar, they are different enough to elicit cross-protection only for a few months after infection by any one of them. Infection with any one serotype confers lifelong immunity to the virus serotype ${ }^{(5)}$ All four serotypes can cause the full spectrum of disease from a subclinical infection to a mild self-limiting disease, the dengue fever (DF) and a severe disease that may be fatal, the dengue haemorrhagic fever/dengue shock syndrome (DHF/ DSS). ${ }^{(6)}$ Immunity based antibody dependent enhancement (ADE) is one of the pathogenesis process, for the severe cause of the disease. (7) Immune enhancement or ADE is observed in dengue virus infection due to heterologous nonneutralising antibodies and carries the potential risk of precipitating serious manifestations like dengue haemorrhagic fever (DHF) or dengue shock syndrome (DSS) during secondary infection by a different serotype. ${ }^{(8)}$

About 2.5 billion people are at risk of dengue, with about 50 to 100 million cases of dengue infections occurring worldwide annually. (7) The epidemiology of dengue fevers in the Indian subcontinent has been very complex and has substantially changed over almost past six decades in terms of prevalent strains, affected geographical locations and severity of disease. ${ }^{(9)}$

The epidemiology of dengue virus and its prevalent serotypes has been ever changing. Dengue virus and its serotypes DENV1 was isolated in 1956 at Vellore. DENV 2 was isolated during the epidemics of dengue in urban and rural areas of Gujarat State during
1988 and 1989.DENV 3 has been isolated during the epidemics at Vellore in 1966, at Calcutta in 1983 and in 1990, at Jalore city Rajasthan in 1985, at Gwalior in 2003 and 2004 and at Tirupur, Tamil Nadu in 2010.The emergence of DENV 4 has been reported in Andhra Pradesh and Pune, Maharashtra which was also implicated in increased severity of disease. ${ }^{(9)}$

At Delhi, till 2003, the predominant serotype was DENV 2 (genotype IV) but in 2003 for the first time all four dengue virus subtypes were found to co-circulate in Delhi thus changing it to a hyper endemic state followed by complete predominance of DENV 3 in 2005. During the 2004 epidemic of DHF/DSS in northern India a sudden shift and dominance of the DENV 3 (subtype III) occurred replacing the earlier circulating serotype-2 (subtype IV). Co-circulation of several serotypes of dengue viruses has resulted in concurrent infection in some patients with multiple serotypes of DENV. Further, replacement of DENV 2 and 3 with DENV 1 as the predominant serotype in Delhi over a period of three years (2007-2009) has been reported. ${ }^{(9)}$

\section{The following are the case definitions as per WHO classification, which were applied for the study}

Suspected clinical case of dengue fever is defined as acute febrile illness with 2 or more of the following: headache, retro orbital pain, myalgia, arthralgia, rash, haemorrhagic manifestations and leucopoenia.

Probable case of dengue is a case compatible with clinical description and with positive IgM antibody test in acute serum specimen.

Confirmed case of dengue fever is defined as a case compatible with clinical description and laboratory confirmed either by detection 
of nucleic acid detection in the serum or NS1 antigen detection by validated immunoassay or fourfold rise in IgM or IgG antibodies in paired samples collected in acute and convalescent stages. ${ }^{(5)}$

The most effective method to diagnose dengue in the acute phase of the illness recommended by the WHO is detection of DENV RNA.RNA is heat-labile and therefore specimens for nucleic acid detection must be handled and stored carefully. ${ }^{(10)}$ DENV can be detected in the blood (serum) from patients for approximately the first 5 days of symptoms. ${ }^{(11)}$

NS1is also a highly specific marker for diagnosis of dengue from day 1 of the fever and there is no need of repeating the test for rising titres. It remains circulating in patient's blood for longer period than does viral RNA and is reported to be detectable even up to 14 th day of illness. ${ }^{(4)}$

Antibody detection by (ELISA) is useful and most popular tool for diagnosis, after 1 week of the fever, but it cannot be used earlier than 3-5 days after the fever nor can be used for discriminating the serotypes. ${ }^{(7)}$

The main aim and objectives of this study to find out the prevalent dengue serotype in the region.

\section{Materials and Methods}

This was a cross-sectional study done from January 2017 to June 2018 at Department of Microbiology, G.M.C, Aurangabad. The patients were evaluated by clinicians for dengue virus infection based on WHO 2009 criteria to identify patients suspected to have dengue.(5) After informed consent, 3-5ml of blood samples from clinically suspected cases(who reported within one to five days of fever) were collected in a container without anti-coagulants. Patient history was taken on structured clinical data sheet provided by NIV, Pune.

Serum was separated from the blood samples by centrifugation. The serum samples were then screened for the presence of dengue NS1 antigen, using Pan Bio NS1Ag ELISA kit and processed according to manufacturer's guidelines

Laboratory confirmed NS1 positive acute phase serum samples, were sent to NIV Pune for serotyping within 72 hours of collection. Those serum samples which could not be processed within 72 hours of collection were stored in the deep freezer at $-80 \mathrm{C}$ until further processed. All samples were transported on dry ice and they were tested by real time RT PCR at National Institute of Virology, Pune for dengue virus RNA\& serotype identification.

\section{Statistical analysis}

The data was collected, compiled and analysed using EPI info (version 7.2). The qualitative variables were expressed in terms of percentages.

\section{Results and Discussion}

A total of 444 acute phase ( $\leq 5$ days of fever) serum samples were collected from clinically suspected dengue fever cases and tested for the presence of dengue NS1 antigen, out of which 71 cases $(15.99 \%)$ were serologically dengue positive and 373 cases (84\%) were negative.

Out of 71 NS1 dengue positive cases, 48 samples were subjected to RT PCR to determine the serotype of dengue virus. 23 samples were not processed *due to insufficient amount of sample regarded by NIV \& Lab (Samples less than 500ul). 
In the present study received 48 reports, out of which total 36 samples were positive by RT PCR \&12 were negative. The differences in RNA \& NS1 antigen detection assays, could suggest individual variation or differences in the timing of these markers in patients serum. ${ }^{(12)}$

Out of 36 samples positive by RT-PCR, serotyping was done of 31 samples \&5 samples positive by RT-PCR could not be serotyped due to low viral load.

On Real time RT-PCR, Dengue virus (DENV) was detected in $75 \%(n=36)$ patients out of 48 analysed samples. Out of 36 RTPCR positive cases, the isolates were equally distributed among children $(<14$ years) and adults, $18(50 \%)$ were children and 18(50\%) were adults. $23(63.88 \%)$ were male and 13 $(36.11 \%)$ were females. Majority of cases i.e.19 $(52.7 \%)$ were seen in the months of September to November 2017 (monsoon \& post monsoon season). Of the 36 patients in whom dengue virus RNA was detected, the following clinical features were seen at the time of presentation: fever in all $36(100 \%)$, low platelet count $[<100,000]$ in $9(25 \%)$, Most of the prominent clinical symptoms include headache 19 (52.7\%), body ache $18(50 \%)$, joint pain $16(44.4 \%)$ and haemorrhagic manifestations $3(8.3 \%)$.

Out of 31serotyped samples, the predominant serotype of DENV detected in our region was DENV-3. 29 cases had single DENV serotype infection and 2 had concurrent infection with two DENV serotypes.13 samples were positive for DENV-3(41.93\%), 8 samples were positive for DENV-4 (25.80\%), 6 samples were positive for DENV-1 (19.35\%), 2 samples were positive for DENV-2 (6.45\%), DENV-2\&3 co-infection was seen in 1 sample $(3.22 \%) \&$ DENV-2\&4 co-infection also in 1 sample (3.22\%). Two out of the thirty-one isolates with DHF/DSS were from patients with DEN 3 infection \& 1 with concurrent infections (DENV 2\&3 coinfection), while the remaining were patients with uncomplicated dengue fever (Fig. 1 and 2; Table 1-4).

Table.1 Samples subjected to RT PCR test

\begin{tabular}{|l|c|c|}
\hline NS1 positive & No. of Cases & Percentage \% \\
\hline Sample processed & 48 & $67.60 \%$ \\
\hline Sample not processed & 23 & $32.39 \%$ \\
\hline Total & 71 & $100 \%$ \\
\hline
\end{tabular}

Table.2 RT-PCR status of processed samples $(n=48)$

\begin{tabular}{|l|c|c|}
\hline RT-PCR & No. of cases/ NS1 positive & Percentage $\%$ \\
\hline Positive & 36 & $75 \%$ \\
\hline Negative* & 12 & $25 \%$ \\
\hline Total & 48 & $100 \%$ \\
\hline
\end{tabular}

Table.3 Serotyping status

\begin{tabular}{|l|c|c|}
\hline Serotyping status & No. of cases & Percentage \\
\hline Serotyping done & 31 & $\mathbf{8 6 . 1 1 \%}$ \\
\hline Serotyping not done* & 5 & $13.88 \%$ \\
\hline Total & 36 & $100 \%$ \\
\hline
\end{tabular}


Table.4 Serotyping result

\begin{tabular}{|l|c|}
\hline Serotype & No. of cases \\
\hline DEN 1 & 6 \\
\hline DEN 2 & 2 \\
\hline DEN 3 & 13 \\
\hline DEN 4 & 8 \\
\hline DEN 2 \& 3 & 1 \\
\hline DEN 2 \& 4 & 1 \\
\hline
\end{tabular}

Fig.1 NS1 Status in suspected dengue fever cases (fever $\leq 5$ days)

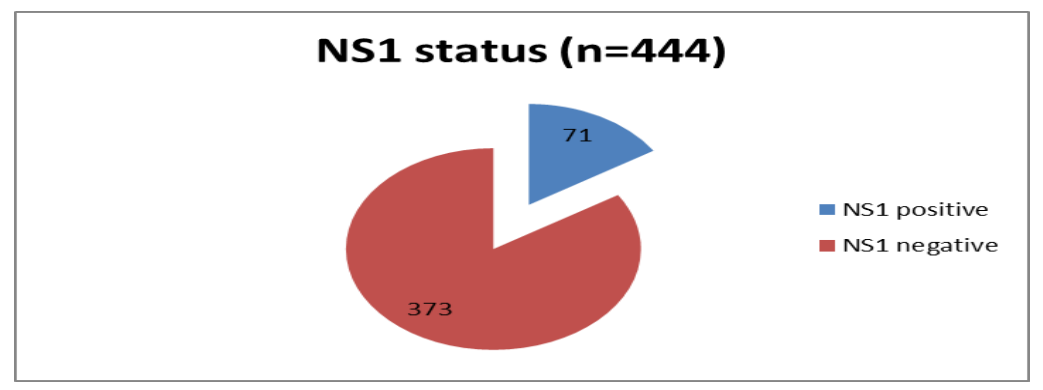

Fig.2 No. of cases showing various dengue serotypes

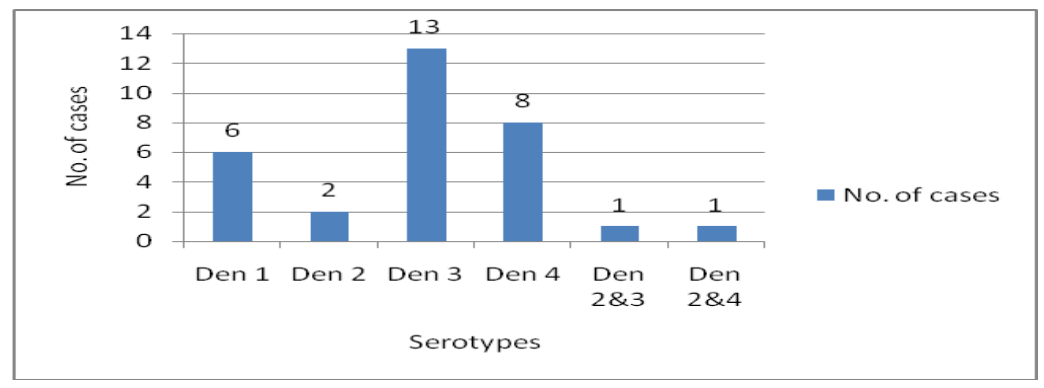

Out of 31 analysed samples for serotyping, there was co-circulation of all the four dengue virus serotypes - DENV-4(25.80\%), DENV-1 (19.35\%), DENV-2 (6.45 \%)with DENV$3(41.93 \%)$ being predominant serotype in our region. In addition, concurrent infection with more than one dengue virus serotype was identified.DENV-2\&3 co-infection \& DENV$2 \& 4$ co-infection was seen in 2 cases.

\section{Findings observed by different studies}

Similarly, DENV-3 remained the predominant serotype in Delhi as reported in 2003-2004. (9)
A study by Chakravati et al., ${ }^{13)}$ detected DENV 1 serotype in their study in Delhi during the year 2008 displacing the previous type $3 \& 2$ prevalent in the previous years.

A study by Ahmed et al., ${ }^{14)}$ detected DENV 1 as the dominant serotype i.e., 33 cases out of $55(60.0 \%)$ and only 1 positive for DENV2.

A study by Borkakoty et al., ${ }^{15)}$ in Arunachal Pradesh North East India, detected predominantly DENV1 (90.9\%) while DENV 2 was detected in $7.5 \%$ of samples. Coinfection of DENV 1 and 2 was detected in one case $(1.51 \%)$. 
In a study by Atif et al., in Pakistan, ${ }^{(16)}$ out of 60 analysed samples, 8 samples were positive for DENV 2 (13.3\%),10 for DENV 3 (16.7\%), 8 samples for DENV 2\&3 coinfection $(13.3 \%), 34$ samples $(56.7 \%)$ were negative for DENV infection. DENV 1 \& DENV 4 was not detected.

In a study by Gupta BP et al., in Nepal, ${ }^{(17)}$ of the 52 acute serum samples tested, 15 were positive in RT PCR. The causative virus was identified as DENV serotype 2.

In Lucknow North India in a study by Pandey et al, (3) 42 samples were tested and DENV 2 and DENV 3 serotypes were detected in 10 and 8 samples, respectively. In 2009, a total of 69 samples were tested and DENV 1 was detected in 5 samples, DENV 2 in 20 samples, and DENV 3 in 15 samples. In 2010, of the 80 serum samples tested, DENV 1 was detected in 16 samples and DENV 2 was detected in 4 samples. DENV 4 was not detected throughout. In a study by Sankari et al., ${ }^{(18)}$ outbreak of dengue virus DENV 2 of Cambodian origin in Manipur, India was seen. In a study by Padhi et al., from southern Odisha India, ${ }^{(19)}$ both DENV1 and DENV2 serotypes were found in a 3year retrospective study.

Concurrent infections with DENV-3 and DENV-1 in 2005, in Delhi were also seen in a study by Gupta et al., (20). Different countries have reported the occurrence of concurrent infections (21-26) in areas where multiple dengue virus serotypes co-circulate. Lower percentage of concurrent infections have also been reported from Taiwan $(9.5 \%)$, Indonesia (11\%) and Mexico, Puerto Rico and Indonesia together $(5.5 \%)^{(21-26)}$.Concurrent infections by multiple dengue virus serotypes may influence the clinical expression of the disease which is considered as a single major factor for the emergence of DHF. ${ }^{(25)}$
The seasonal trend of dengue virus infection is reflected by the peak of positive cases observed during monsoon \&post monsoon season i.e. September-November which is in concordance with studies by Padhi et al., (19) and Bandyopadhyay et al., ${ }^{(6)}$ who also observed maximum cases during the monsoon and post-monsoon seasons.

The 1996 outbreak of DHF/DSS in Delhi identified dengue virus type 2 as the etiologic agent. $^{(27)}$

DEN-3 has been reported as the aetiology of the first major DHF outbreak in neighbouring Bangladesh in $2001^{(28)}$ and also implicated in various outbreaks of DHF in Srilanka, East Africa and Latin America ${ }^{(29)}$

*Thus, case with concurrent infection had severe disease, though the number is small and larger studies are needed to prove this association.

In conclusion the detection of dengue virus RNA by RT-PCR showed that DENV-3 was the most common etiologic agent even though all the four dengue virus serotypes were found to co-circulate. This is the first study conducted in Aurangabad and this data will also assist in completing the dengue serotype map of India. Also there is need of long term studies with analysis of dengue serotypes to know more about the epidemiological, demographic and biological variations of dengue cases in this region. The study will also help to understand the evolutionary processes influencing the dengue virus and may impact on vaccination strategies for future.

\section{Acknowledgement}

First \& foremost, thanks to the Lord Almighty Jehovah, throughout the work which shaped the present work as it shows. A debt of 
gratitude is owed to National Institute of virology (NIV, Pune) for their constant help and support $\&$ to all other departmental staff.

\section{Funding: None}

Conflict of interest: None declared

Ethical approval: The study was approved by the Institutional Ethics Committee.

Abbreviations: DHF: Dengue Haemorrhagic Fever; DF: Dengue Fever; ELISA: Enzyme Linked Immunosorbent Assay; DENV: Dengue Virus; DSS: Dengue shock syndrome; RT PCR: Reverse transcriptase Polymerase Chain Reaction

\section{References}

Ahmed NH, Broor S. Dengue Fever Outbreak in Delhi, North India: A ClinicoEpidemiological Study. 2015; 40(2).

Badave GK, Swaroop PS, Rao PN. Importance of NS1 antigen detection and its association with platelet count for early diagnosis of dengue virus infection. Int $\mathbf{J}$ Curr Microbiol Appl Sci. 2015; 4(March):779-84.

Bandyopadhyay B, Bhattacharyya I, Adhikary S, Konar J, Dawar N, Sarkar J, et al., A Comprehensive Study on the 2012 Dengue Fever Outbreak in Kolkata, India [Internet]. Vol. 2013, ISRN Virology. 2013. p. 1-5. Available from: http://www.hindawi.com/ journals/isrn/ 2013/207580/

Borkakoty B, Das M, Sarma K, Jakharia A, Das $\mathrm{PK}$, Bhattacharya $\mathrm{C}$, et al., Molecular Characterisation and Phylogenetic Analysis of Dengue Outbreak in Pasighat, Arunachal Pradesh, Northeast India. 2018;37-42.

Chakravarti A, Kumar A, Matlani M. Displacement of dengue virus type 3 and type 2 by dengue virus type 1 in Delhi during 2008. Indian J Med Microbiol $1010 ; 28 ; 412$
Chaturvedi UC NR. Dengue in India. J Biosci. 2008; 33(4): 373-90.

Dar L, Broor S, Sengupta S, Xess I, Seth P. The first major outbreak of dengue hemorrhagic fever in Delhi, India. Emerging infectious diseases. 1999 Jul; 5(4): 589.

Dar L, Ghosh A. Dengue vaccines: Challenges, development, current status and prospects. Indian J Med Microbiol [Internet]. 2015; 33(1):3. Available from: http://www.ijmm.org/text.asp?2015/33/1/ 3/148369

Diagnosis GFOR. New edition 2009. 2009; Laboratory Guidance and Diagnostic Testing Dengue CDC. Available from: https://www.cdc.gov/dengue/clinicallab/la boratory.html

Fang M, Chen C, Chen H, Tian X, Jiang L, Rao $\mathrm{Y}$, Guo $\mathrm{H}$ : Detection of flaviviruses by reverse transcriptase-polymerase chain reaction with the universal primer set. Microbiol Immunol 1997,41:209-213.

Gupta E, Dar L, Kapoor G, Broor S: The changing epidemiology of dengue in Delhi, India. Virology Journal 2006, 3:92.

Kanesa-Thasan N, Chang GJ, Smoak BL, Magill A, Burrous MJ, Hoke CHJr: Molecular and epidemiologic analysis of dengue virus isolates from Somalia. Emerg Infect Dis 1998, 4(2):299-303.

Kong YY, Thay CH, Tin TC, Devi S. Rapid detection, serotyping and quantitation of dengue viruses by TaqMan real-time onestep RT-PCR. J Virol Methods. 2006; 138(1-2):123-30.

Laille M, Deubel V, Sinte-Marie FF: Demonstration of concurrent dengue 1 and dengue 3 infection in six patients by the polymerase chain reaction. $\mathrm{J}$ Med Virol 1991, 34:51-54.

Loroño-Pino MA, Cropp CB, Farfán JA, Vorndam AV, RodriguezAngulo EM, Rosado-Paredes EP, Flores-Flores LF, Beaty BJ, Gubler DJ: Common occurrence of concurrent infections by multiple dengue virus serotypes. Am J Trop Med Hyg 1999, 61(5):725-730.

Maneekarn N, Morita K, Tanaka M, Igarashi A, 
Usawattanakul W, Sirisanthana V, Innis BL, Sittisombut N, Nisalak A, Nimmanitya S: Applications of polymerase chain reaction for identification of dengue viruses isolated from patient sera. Microbiol Immunol 1993, 37:41-47.

Messer WB, Gubler DJ, Harris E, Sivananthan K, De Silva AM. Emergence and global spread of a dengue serotype 3, subtype III virus. Emerging infectious diseases. 2003 Jul; 9(7): 800.

NVBDCP. Guidelines for Clinical Management of DF, DHF and DSS. 2008;

Padhi S, Dash M, Panda P, Parida B, Mohanty I, Sahu S, Narasimham MV. A three year retrospective study on the increasing trend in seroprevalence of dengue infection from southern Odisha, India. The Indian journal of medical research. 2014 Nov;140(5):660.

Pandey N, Nagar R, Gupta S, Omprakash, Khan $\mathrm{D}$, Singh DD, et al., Trend of dengue virus infection at Lucknow, north India (2008- 2010): A hospital based study. Indian J Med Res. 2012; 136(5): 862-7.

Paudel D, Jarman R, Limkittikul K, Klungthong C, Chamnanchanunt S, Nisalak A, et al., Comparison of real-time SYBR green dengue assay with real-time taqman RTPCR dengue assay and the conventional nested PCR for diagnosis of primary and secondary dengue infection. N Am J Med Sci. 2011;3(10):478-85.
Rahman M, Rahman K, Siddque AK, Shoma S, Kamal AH, Ali KS, Nisaluk A, Breiman RF. First outbreak of dengue hemorrhagic fever, Bangladesh. Emerging infectious diseases. $2002 \mathrm{Jul} ;$ 8(7):738.

Sankari T, Hoti SL, Singh TB, Shanmugavel J. Outbreak of dengue virus serotype-2 (DENV-2) of Cambodian origin in Manipur, India-Association with meteorological factors. The Indian journal of medical research. 2012 Oct; 136(4):649.

Scott WB. Enhanced lantirn. Aviat Week SpTechnol (New York). 2003;159(3):448.

Sushma G, Lakshmi R, Nagamani K, Soujanyai KN, Rani M, Pakalapaty S, et al., A Study on NS1 Antigen Detection ELISA Assay in Comparison with RNA Detection by Reverse Transcription Polymerase Chain Reaction for the Early Diagnosis of Dengue. IntJCurrMicrobiolAppSci. 2017;6(12):1586-96.

Wang WK, Chao DY, Lin SR, Chang SC: Concurrent infections by two dengue virus serotypes among dengue patients in Taiwan. J Microbiol Immunol Infect 2003, 36:89-95.

Waqar AB. Serotyping of Dengue Virus from Deadly Outbreaks of Pakistan. J Hum Virol Retrovirology [Internet]. 2016; 3(3):1-7. Available from: http://medcraveonline.com/JHVRV/JHVR V-03-00092.php.

\section{How to cite this article:}

Vanlalhmingthanpuii, Jayshree B. Bhakre, Jyoti A. Iravane, Ajit S. Damle and Pankaj A. Joshi. 2020. Prevalent Dengue Serotypes in and around Aurangabad, Maharashtra, India. Int.J.Curr.Microbiol.App.Sci. 9(11): 2186-2193. doi: https://doi.org/10.20546/ijcmas.2020.911.260 